\title{
Insight into the role of interfacial reconstruction of manganese oxides toward enhanced electrochemical capacitors
}

\author{
Jie Zhang ${ }^{\mathrm{a}, \mathrm{b}}$, Wenli $\mathrm{Li}^{\mathrm{a}}{ }^{\mathrm{b}}$, Dandan $\mathrm{Hu}^{\mathrm{a}}$, Tofik Ahmed Shifa ${ }^{\mathrm{c}}$, Shuaichao Chen ${ }^{\mathrm{a}}$, Guangwen $\mathrm{Xu}^{\mathrm{a}}$, \\ Yanbin Cui ${ }^{\mathrm{a}, \mathrm{b}, *}$ \\ ${ }^{a}$ State Key Laboratory of Multiphase Complex Systems, Institute of Process Engineering, Chinese Academy of Sciences, Beijing 100190, China \\ ${ }^{\mathrm{b}}$ Center of Materials Science and Optoelectronics Engineering, University of Chinese Academy of Sciences, Beijing 100049, China \\ ${ }^{\mathrm{c}}$ CAS Center for Excellence in Nanoscience, CAS Key Laboratory of Nanosystem and Hierarchical Fabrication, National Center for Nanoscience and Technology, Beijing \\ 100190, China
}

\section{H I G H L I G H T S}

- Multi-layered sawtooth-shape $\mathrm{MnO}_{2}$ with relatively high mass loading is fabricated.

- The S-MnO${ }_{2}$ /ACC exhibits high capacitance and excellent cycling stability.

- An acid-induced layer-to-tunnel transition method of $\mathrm{MnO}_{2}$ is designed.

- The flexible device with a wide operating voltage of $2.2 \mathrm{~V}$ delivers a volumetric energy density of $4.3 \mathrm{mWh} /$ $\mathrm{cm}^{3}$.

\section{A R T I C L E I N F O}

\section{Keywords:}

Sawtooth-shape $\mathrm{MnO}_{2}$

Activated graphene

Cycling stability

Asymmetric supercapacitor

Interfacial reconstruction

\section{G R A P H I C A L A B S T R A C T}

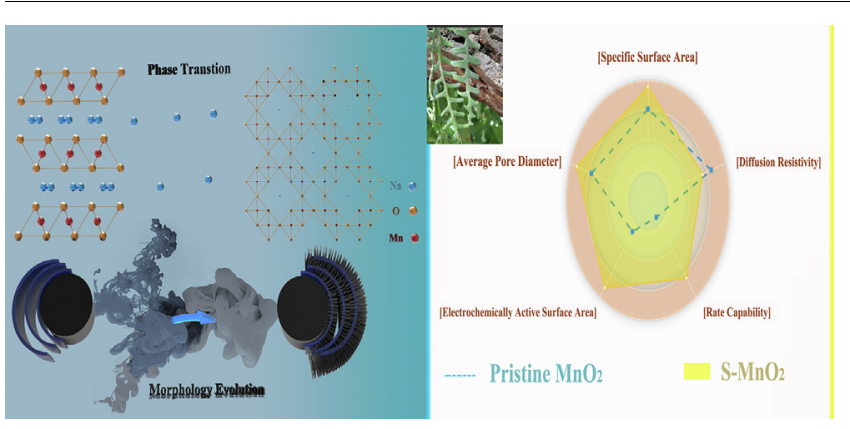

\begin{abstract}
A B S T R A C T
The pursuit of facile synthetic methods for systematic control over the morphology and crystal phase of nanostructures has attracted a tremendous amount of interest. By utilizing the acid-induced layer-to-tunnel transition method of $\mathrm{MnO}_{2}$, we here for the first time report multi-layered sawtooth-shape $\mathrm{MnO}_{2}$ with relatively high mass loading. The optimized electrode exhibits durable activity with enhanced surface area, electrical conductivity and ionic diffusion. A high areal capacitance of $1781.8 \mathrm{mF} / \mathrm{cm}^{2}$ is obtained and excellent rate performance can be corroborated from capacitance retention of $64.1 \%$ when the current density is increased by 45 fold. Our uniquely assembled heterostructure endows a large number of active sites and acts as electron superhighways to facilitate efficient charge transportation. Further coupling with activated graphene/CC anode, a flexible device with a maximum operating voltage of $2.2 \mathrm{~V}$ is assembled, delivering a high volumetric energy density of $4.3 \mathrm{mWh} / \mathrm{cm}^{3}$ at a power density of $27.6 \mathrm{~mW} / \mathrm{cm}^{3}$ with outstanding cycling performance. The finding promotes the development of highly efficient faradaic electrode materials toward closing the gap between achieved and theoretical capacitance without limiting the mass loading.
\end{abstract}

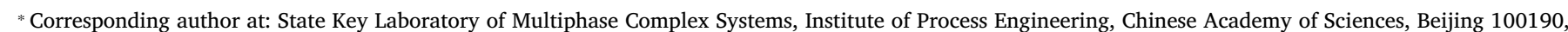
China.

E-mail address: ybcui@ipe.ac.cn (Y. Cui). 


\section{Introduction}

The escalating demand for portable and implantable electronics necessitates the development of new generation high-performance energy storage devices [1-4]. Electrochemical supercapacitors, as one sector of promising energy devices, have the ability to bridge the gap of traditional electrostatic capacitors and batteries. This triggers enthusiasm for their development of high mass loading and wide operating window [5-11]. However, this research trend is challenged by the significant deterioration of rate capability with increasing film thickness which is naturally accompanied by electronic relaxation through the cross-section, hence leading to moderate electrical conductivity and restricted ion diffusion into the interior structure $[12,13]$. For instance, manganese oxide by the virtue of high theoretical specific capacitance arising from Faradaic charge/transfer reactions has aroused tremendous interest. Nevertheless, the electrons are not able to penetrate $\mathrm{MnO}_{2}$ when the thickness is more than $\sim 400 \mathrm{~nm}$ because of its electrically insulating in nature, which remains a big challenge for the realization of experimental specific capacitance $[14,15]$.

$\mathrm{MnO}_{2}$ have multiple polymorphs based on the stacking and connecting fashion among the basic $\left[\mathrm{MnO}_{6}\right]$ octahedral units, including the $1 \times 1$ tunnel structured $\beta-\mathrm{MnO}_{2}, 2 \times 2$ tunnels structured $\alpha-\mathrm{MnO}_{2}$, and $2 \times \infty$ layered structured $\delta-\mathrm{MnO}_{2}$, etc [16]. This structural flexibility is attributed to the ease conversion between $\mathrm{Mn}^{4+}$ and $\mathrm{Mn}^{3+}$ oxidation states $[17,18]$. Whereas, single-phase $\mathrm{MnO}_{2}$ suffering from poor electronic/ionic transport and hence could not provide satisfactory specific capacitance and cycling stability [19]. In such context, heterojunction nanostructures with multiple phases have been attempted instead of building simple homogenous structures [3]. This does not only enhance the rate capability of active materials but also ensures the stability for long term application. For instance, Zhu et al. reported $\alpha-\mathrm{MnO}_{2} @ \delta$ $\mathrm{MnO}_{2}$ core-branch structure which exhibited an ultrahigh areal capacitance up to $783 \mathrm{mF} / \mathrm{cm}^{2}$ at $1 \mathrm{mV} / \mathrm{s}$ with excellent cycle lives of $\sim 86 \%$ capacitance retained after 20,000 charge/discharge cycles [20]. Huang and co-workers successfully synthesized a material of $\alpha-\mathrm{MnO}_{2} @ \varepsilon-\mathrm{MnO}_{2}$ hierarchical nanostructures with high mass loading, which ensure facile ionic and electric transport, far exceeding the capacity of most manganese oxide-based electrodes in neutral electrolytes [12]. Moreover, $\delta$ $\mathrm{MnO}_{2}$ grew directly on $\beta-\mathrm{MnO}_{2}$ was synthesized by Zhu's group achieving high electrochemical performances $\left(657 \mathrm{~F} / \mathrm{g}\right.$ in $1 \mathrm{M} \mathrm{Na}_{2} \mathrm{SO}_{4}$ electrolyte) where in the potential window can be enlarged to $2.2 \mathrm{~V}$ when assembling an asymmetric supercapacitor [21]. Despite these intriguing observations, apparently, there are still plenty of rooms to further optimize the structure and morphology of manganese oxides by chasing better efficiency and stability toward energy storage, especially for flexible electronics. Meanwhile, tuning the ratio of $\mathrm{Mn}^{3+} / \mathrm{Mn}^{4+}$ can efficiently augment the stability of $\mathrm{MnO}_{2}$. In edge-sharing $\mathrm{MnO}_{6}$ octahedra, $\mathrm{Mn}^{3+}$ is expected to be unstable due to the presence of single electron in the $\mathrm{e}_{\mathrm{g}}$ band $\left(\mathrm{t}_{2 \mathrm{~g}}{ }^{3}, \mathrm{e}_{\mathrm{g}}{ }^{1}\right)$ [22]. Owing to the Jahn-Teller distortion of the $\mathrm{Mn}(\mathrm{III}) \mathrm{O}_{6}$ octahedron, $\mathrm{MnO}_{\mathrm{x}}$ involving trivalent $\mathrm{Mn}$ shows rather a lower conductivity in comparison with $\mathrm{MnO}_{2}$ or amorphous manganese oxides involving tetravalent $\mathrm{Mn}$, leading to rapid capacity degradation [23-25].

Stimulated by these considerations, a facile electrodeposition technique and a post-hydrothermal treatment were designed to fabricate multi-layered sawtooth-shape $\mathrm{MnO}_{2}\left(\mathrm{~S}-\mathrm{MnO}_{2}\right)$ with almost no stacking on activated carbon cloth (ACC), as previously noted [26], through interfacial reconstruction. To the best of our knowledge, this has never been reported so far and would represent a significant input in the development of functional materials in energy sector. In this scenario, the pathways of electrons and ions in the active material could be extremely shortened by exposing more hidden $\mathrm{MnO}_{2}$ area in each layer and those newly formed efficient electrical connection. The optimized $\mathrm{S}-\mathrm{MnO}_{2} /$ ACC electrode composed of heterojunctions of $\alpha$ - and $\delta$-phase $\mathrm{MnO}_{2}$ shows all-round raising of electrochemical performance than the pristine one. Additionally, the resultant flexible asymmetric supercapacitor composed of S-MnO $2 /$ ACC (positive electrode) and activated graphene/CC (negative electrode) can deliver a high volumetric energy density of $4.3 \mathrm{mWh} / \mathrm{cm}^{3}$ at a power density of $27.6 \mathrm{~mW} / \mathrm{cm}^{3}$, and an excellent capacitance retention of $91.2 \%$ after 20,000 cycles in a stable voltage window of $0-2.2 \mathrm{~V}$, showing the potential for practical application.

\section{Experimental section}

\subsection{Preparation of $\mathrm{S}-\mathrm{MnO}_{2} / \mathrm{ACC}$}

All chemicals used in the experiment were of analytical grade without further purification. First, as previously reported [26], the pristine $\mathrm{MnO}_{2}$ electrode was synthesized by applying a high-voltage electrodeposition method. Specifically, a piece of carbon cloth $\left(2 \times 1 \mathrm{~cm}^{2}, 0.33 \mathrm{~mm}\right.$ in thickness) was used as working electrode in a precursor solution of $\mathrm{MnSO}_{4} \cdot \mathrm{H}_{2} \mathrm{O}(0.4 \mathrm{M})$ and $\mathrm{Na}\left(\mathrm{CH}_{3} \mathrm{COO}\right)_{2}(0.6 \mathrm{M})$ at a constant potential of $3 \mathrm{~V}$ for $180 \mathrm{~s}$ (Temperature: $\sim 30{ }^{\circ} \mathrm{C}$ ). The electrode was then immersed in $50 \mathrm{~mL}$ of $0.35 \mathrm{M} \mathrm{H}_{2} \mathrm{SO}_{4}$ aqueous solution fixed by adhesive tapes. Subsequently, the total solution was transferred into a stainless-steel autoclave with a capacity of $100 \mathrm{~mL}$ in a Teflon-lined autoclave, sealed and heated at $60{ }^{\circ} \mathrm{C}$ for different reaction times. The reaction time was controlled to be 12, 18, 24 and $48 \mathrm{~h}$, and the samples were labeled as S- $\mathrm{MnO}_{2}-12, \mathrm{~S}-\mathrm{MnO}_{2}-18, \mathrm{~S}-\mathrm{MnO}_{2}-$ 24 , and $\mathrm{S}-\mathrm{MnO}_{2}-48$. The mass loading of $\mathrm{MnO}_{2}$ was measured by calculating the weight difference of the electrodes using a high precision balance $(0.001 \mathrm{mg})$ following each synthesis step.

\section{Fabrication of flexible asymmetric supercapacitor}

Activated graphene/CC (AGe/CC) negative electrode was fabricated by electrochemical activation of graphene slurry/CC (graphene, PTFE, and Super $\mathrm{P}$ in a ratio of 8:1:1 with N-methyl-2-pyrrolidone) in a mixed acid of $\mathrm{HNO}_{3}$ and $\mathrm{H}_{2} \mathrm{SO}_{4}(\mathrm{~V} / \mathrm{V}=1: 1)$ using three-electrode system containing a platinum sheet as counter electrode and a saturated calomel electrode (SCE) as a reference electrode under a constant voltage of $3 \mathrm{~V}$. Prior to assembling, a piece of cellulose paper (NKK-MPF30AC100 , Japan) was soaked in a $1 \mathrm{M} \mathrm{Na}_{2} \mathrm{SO}_{4}$ aqueous solution for $10 \mathrm{~min}$ and then carefully entangled with the $\mathrm{S}-\mathrm{MnO}_{2} / \mathrm{ACC}$ and $\mathrm{AGe} / \mathrm{CC}$. Eventually, a thin parafilm was wrapped on the asymmetric supercapacitor.

\section{Materials characterization}

The morphology and microstructure of the samples were characterized by scanning electronic microscope (SEM, JEM-7001F) and transmission electron microscope (TEM, JEOL-2100). The crystallographic structures were investigated by a Rigaku Smartlab X-ray diffractometer using $\mathrm{Cu} \mathrm{K} \alpha$ radiation. Raman spectra were recorded by a confocal laser inVia Raman microscope (Renishaw, $\lambda \mathrm{e}=514 \mathrm{~nm}$ ). The pore size distribution curve was produced from the isotherm by Density Functional Theory (NLDFT) methods. Surface composition was analyzed by X-ray photoelectron spectroscopy (XPS, ESCALAB 250Xi, Thermal-Fisher). The water contact angle was measured by the optical contact angle measurement system (DSA100S, KRUSS GmbH, Germany). Cyclic voltammetry (CV), galvanostatic charge/discharge (GCD), as well as electrochemical impedance spectroscopy (EIS) of the individual electrode were implemented by a familiar three-electrode system with a Pt counter electrode and a SCE reference electrode.

\section{Results and discussions}

During the synthesis of pristine $\mathrm{MnO}_{2}$, the applied high voltage leads to the rapid formation of abundant nuclei of $\mathrm{MnO}_{2}$ in a short time [26]. The inner nanoparticles in each lamella of pristine $\mathrm{MnO}_{2}$ tend to inevitably aggregate and stack due to high surface energy [27], which 


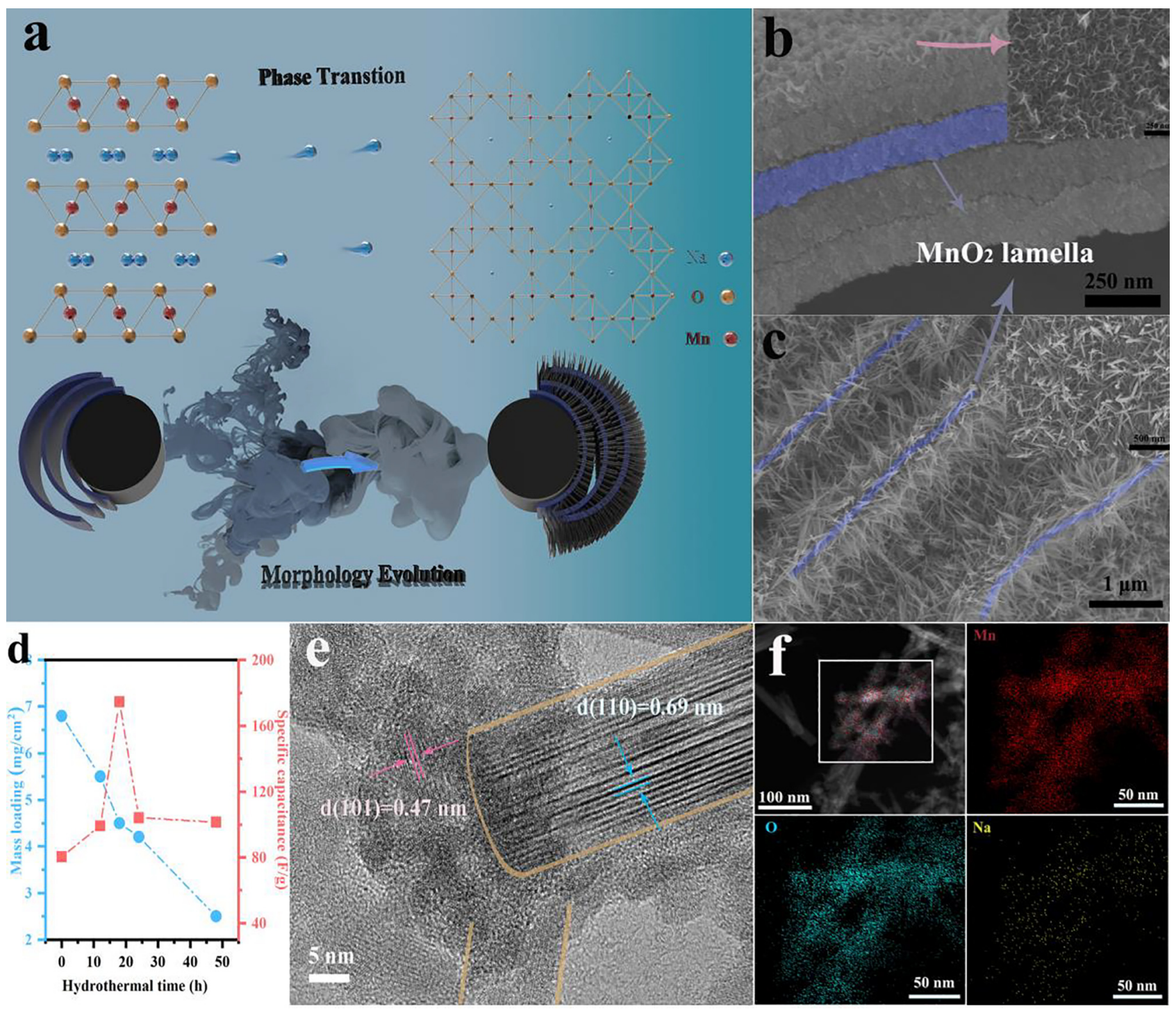

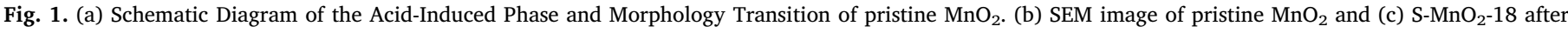

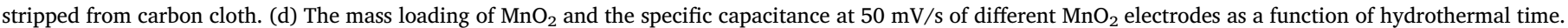
(e) HR-TEM image of S-MnO 2 . (f) EDX mapping images of the different elements $\mathrm{Mn}, \mathrm{O}$, and Na.

may hinder efficient access to active sites by electrolyte and further increases the diffusion resistance. Dilute sulfuric acid as solution in hydrothermal process was used for tuning the morphology of pristine $\mathrm{MnO}_{2}$ for better utilization of active material. Fig. 1a illustrates a nanoparticle@nanoneedle hierarchical structure such that the thermodynamically favored product consists of tunnel $\mathrm{MnO}_{2}$ nanostructure whose corner/edges are shared by $\mathrm{MnO}_{6}$ octahedral entity.

Fig. 1b shows concentric lamellae along with ultrathin $\mathrm{MnO}_{2}$ nanosheets on the surface of pristine $\mathrm{MnO}_{2}$. After being hydrothermally reacted with $0.35 \mathrm{M} \mathrm{H}_{2} \mathrm{SO}_{4}$ for an initial $12 \mathrm{~h}$, similar lamellae are observed with a small amount of needle-like $\mathrm{MnO}_{2}$ on the top (Fig. S1a). When extending the reaction time, more $\mathrm{MnO}_{2}$ nanoneedles are grown by sacrificing pristine $\mathrm{MnO}_{2}$ (Fig. S1b, c). With the advancement of surface reconstruction, more buried sites can be exposed on the surface, evidenced by the increment of specific surface area (inset in Fig. S1c). However, the excessive reaction time may result in the collapse of the $\mathrm{MnO}_{2}$ lamellae, which causes a dramatic decrease of specific surface area and capacitance. Still, the capacitance of each electrode after acid treatment is higher compared with pristine $\mathrm{MnO}_{2}$ (Fig. S1d, 1d), as a result of extra pseudo-capacitance. Taking into consideration the necessary compromise between the mass loading and specific capacitance, $\mathrm{S}-\mathrm{MnO}_{2}-18$ was chosen for further study. As illustrated in Fig. 1c, secondary $\mathrm{MnO}_{2}$ nanoneedles are aligned almost vertically on both sides of the original nanoparticles and the adequate combination of nanoparticles and nanoneedles forms a more continuous skeleton facilitating electron transfer in the electrode [12,28]. The nanoneedles with no obvious aggregation have a smooth surface and a length up to hundreds of nanometers (Fig. S2), which endows 1D electronic pathways for efficient charge transport and may accommodate the volume change during the electrochemical reactions [29]. For deeper insight into this hierarchical structure, we employed HRTEM analysis (Fig. 1e) and directly observed that the diameter of the nanoneedles ranges from 20 to $30 \mathrm{~nm}$. Well-resolved lattice fringes can be seen from both nanostructures and the measured lattice distance of 0.47 and $0.69 \mathrm{~nm}$ can be correlated to the lattice spacing of the $\left(\begin{array}{lll}1 & 0 & 1\end{array}\right)$ facet of primary nanoparticles and (1 110$)$ facet of secondary nanoneedles, respectively. Additionally, EDS mapping obtained from the TEM measurements (Fig. 1f) displays a homogeneous spatial distribution of elements $\mathrm{Mn}, \mathrm{O}$, and $\mathrm{Na}$ throughout the nanoneedles.

The phase evolution was studied by XRD and Raman spectroscopy. The sharp peak centered at around $25^{\circ}$ corresponds to typical $\left(\begin{array}{lll}0 & 0 & 2\end{array}\right)$ interlayer peak of carbon cloth substrate. For pristine $\mathrm{MnO}_{2}$, the 

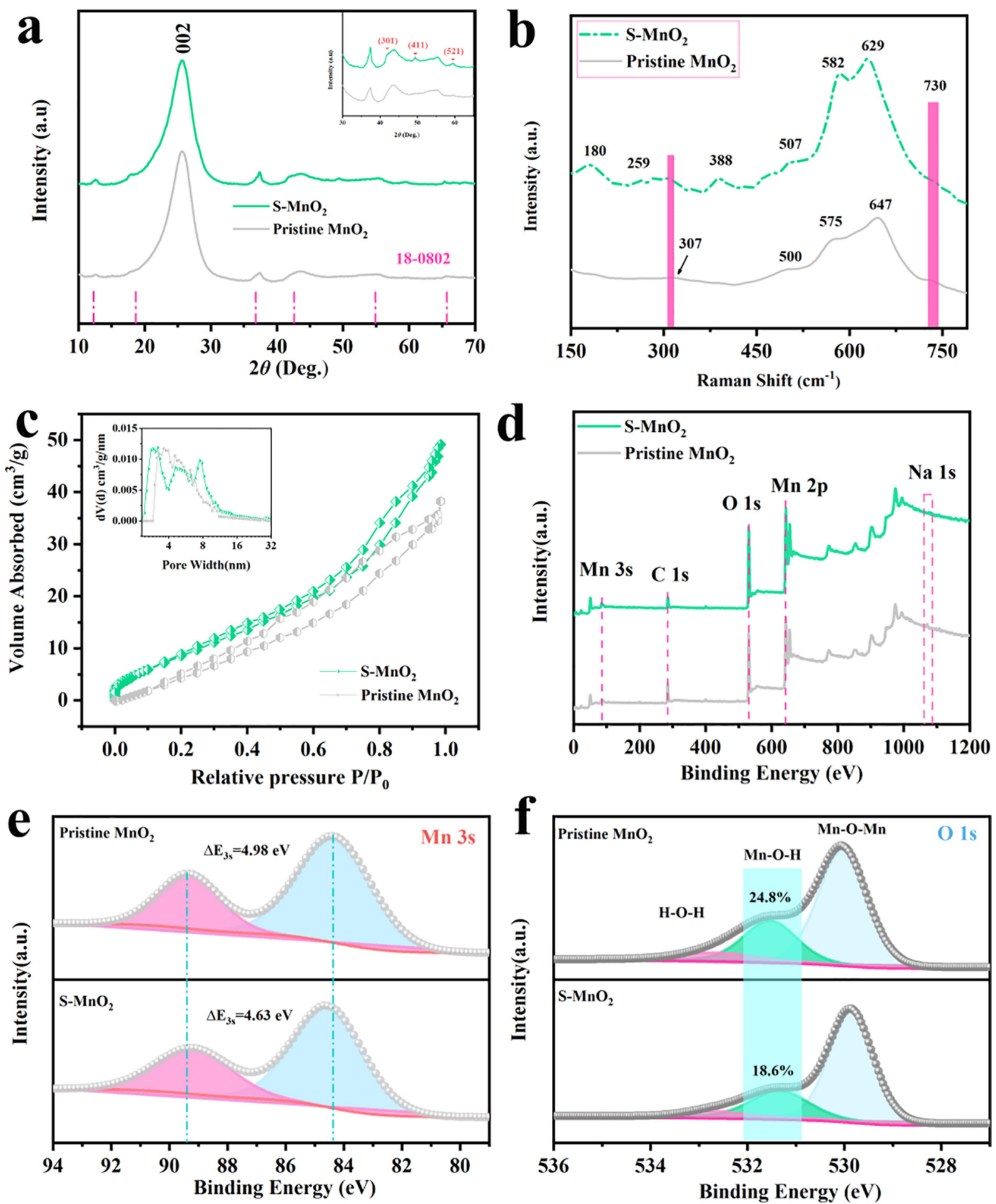

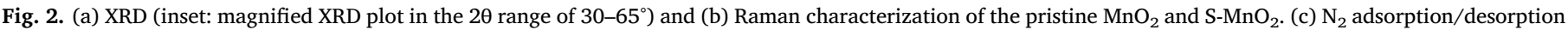
isotherms (inset: pore-size distribution curve). Comparative XPS spectra. (d) Survey spectrum, (e) Mn $3 \mathrm{~s}$, and (f) O 1s.

diffraction peaks located at $12.6^{\circ}, 18.2^{\circ}, 37.4^{\circ}, 54.9^{\circ}$, and $65.7^{\circ}$ (Fig. 2a) can be well-indexed to $\delta-\mathrm{MnO}_{2}$ (JCPDS 18-0802, space group: hexagonal $\mathrm{R} \overline{3} \mathrm{M})$. The low intensity of these peaks is an indication of poor crystallinity [26]. Lower crystallinity can result in a highly porous microstructure to facilitate ion accessibility and cation diffusion, loss of electrical conductivity occurs simultaneously. Inspired by previous works $[12,20,28]$, hetero-phase junction is expected to improve the overall electric conductivity. After acid-induced process, the $\alpha-\mathrm{MnO}_{2}$ phase (JCPDS 44-0141) appears with three additional characteristic peaks at about $41.8^{\circ}, 49.3^{\circ}$, and $59.4^{\circ}$, in addition to the presence of the $\delta$ - $\mathrm{MnO}_{2}$ phase. As been widely accepted $[30,31]$, the layered structure of the $\delta-\mathrm{MnO}_{2}$ appears in a metastable state owing to weak interlayer interaction as well as narrower valence and conduction band than other polymorphs [32-34]. This provides a conducive environment to tune the crystallographic phase accompanied by surface restructuring. Under the hydrothermal condition $\left(\mathrm{H}_{2} \mathrm{SO}_{4}\right.$ solution), a dissolution-crystallization process is carried out. Meanwhile, the nanosheets on the surface tend to collapse and transform into stable tunnel structure without 

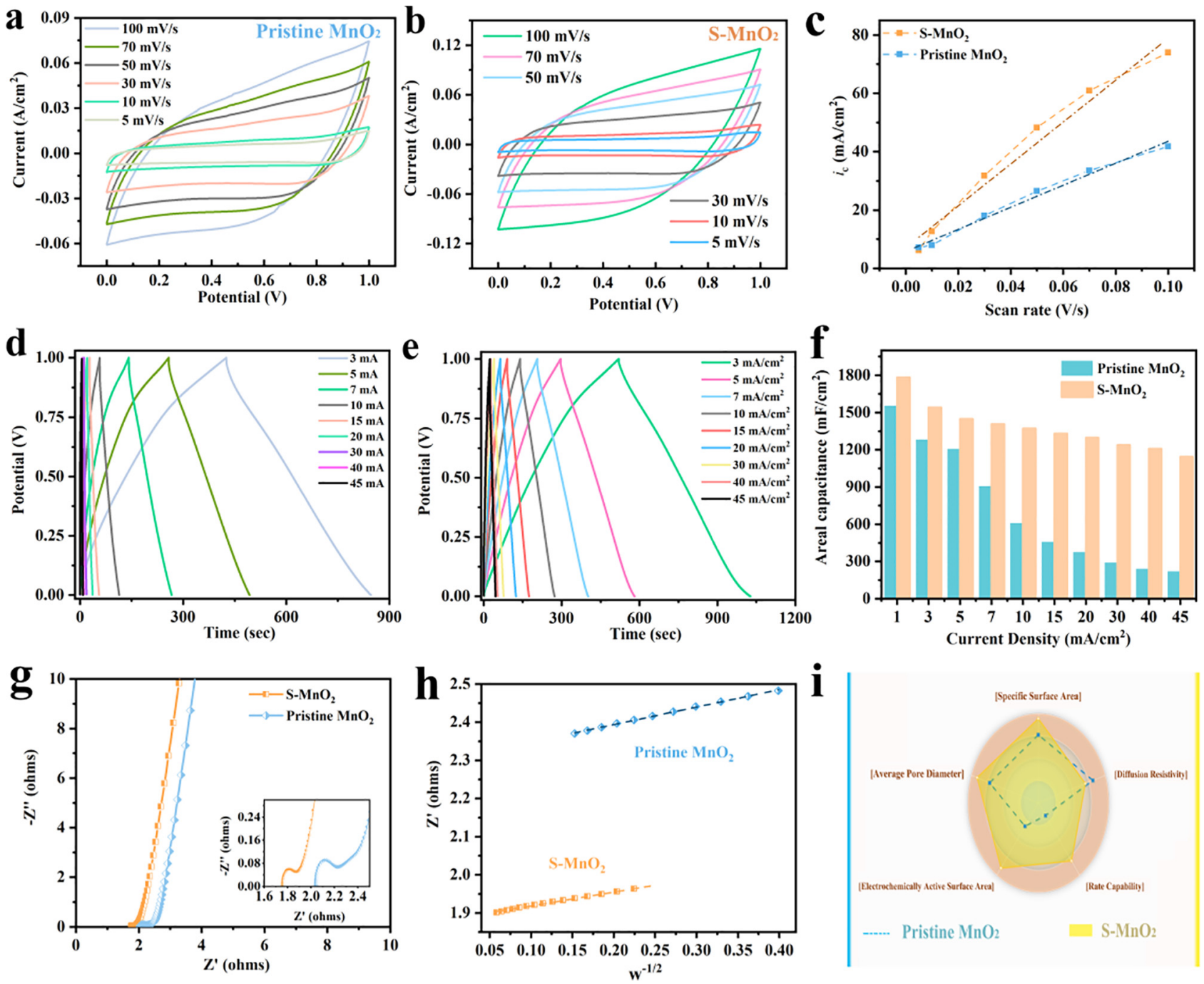

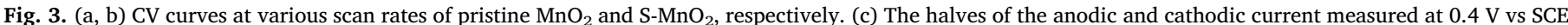

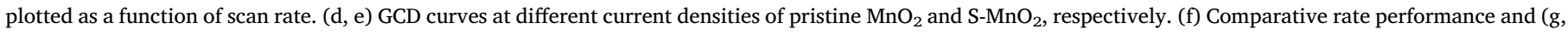
h) EIS measurement of pristine $\mathrm{MnO}_{2}$ and S- $\mathrm{MnO}_{2}$. (i) The comparison chart of the five parameters for pristine $\mathrm{MnO}_{2}$ and S-MnO $\mathrm{M}_{2}$.

abundant $\mathrm{Na}^{+}$cations, which may serve as the original driving force to converts less ordered particles to nanoneedles [35]. Raman spectra give a powerful evidence for the existence of hetero-phase system. According to the preliminary assignments of signals by Julien et al. [36], two high-wavenumber Raman bands (575 and $647 \mathrm{~cm}^{-1}$ ) and a rather weak one $\left(500 \mathrm{~cm}^{-1}\right)$ are detected for layered $\delta-\mathrm{MnO}_{2}$, while two highfrequency bands at around 582 and $629 \mathrm{~cm}^{-1}$ are characteristic of the tunnel structured $\mathrm{MnO}_{2}$ (Fig. 2b) $[37,38]$. The reserved peaks located at 307 and $730 \mathrm{~cm}^{-1}$ validate the existence of $\delta-\mathrm{MnO}_{2}$. Both XRD and Raman results indicate that the acid-induced process enables a gradual phase transition from $\delta-\mathrm{MnO}_{2}$ to $\alpha-\mathrm{MnO}_{2}$, which is further accompanied by the increase in specific surface area from BET analysis (Fig. 2c). The specific surface areas are $40.8 \mathrm{~m}^{2} / \mathrm{g}$ and $55.4 \mathrm{~m}^{2} / \mathrm{g}$ for pristine $\mathrm{MnO}_{2}$ and $\mathrm{S}-\mathrm{MnO}_{2}$, respectively. Both exhibit a typical type-IV isotherm with a hysteresis loop in intermediate relative pressure range, indicating the presence of mesopores. The corresponding average pore diameter (inset in Fig. 2c) revealed clearly by the DFT method shifts from $\approx 5.8$ to $\approx 7.3 \mathrm{~nm}$ after acid treatment. The noticeable improvement in surface area and average pore diameter realize that interfacial reconstruction could be of great benefit for the swift diffusion, transportation, and intercalation of electrolyte ions throughout the electrode [39].

X-ray photoelectron spectroscopy (XPS) was conducted to further investigate the chemical composition and valence states of $\mathrm{S}-\mathrm{MnO}_{2}$.
Characteristic peaks corresponding to $\mathrm{Mn}, \mathrm{O}, \mathrm{Na}$ and $\mathrm{C}$ are apparent in the overview profile (Fig. 2d). Generally, the intercalated species, such as $\mathrm{K}^{+}, \mathrm{Na}^{+}$, or $\mathrm{NH}_{4}{ }^{+}$, inside $\mathrm{MnO}_{2}$ are mobile and not present in the skeleton [33]. With the incorporation of remnant $\mathrm{Na}^{+}$into its $2 \times 2$ tunnel structure, which needs fewer cations to be stable, the hierarchical $\alpha-\mathrm{MnO}_{2} / \delta-\mathrm{MnO}_{2}$ possesses a higher average oxidation state (AOS) of manganese for charge neutralization [34]. This can be unequivocally proved by XPS analysis on the Mn chemical states. Different from $\mathrm{Mn} 2 \mathrm{p}$ spectrum, which shows a similar spin-energy separation of $11.8 \mathrm{eV}$ (Fig. S3a), analysis on the Mn $3 \mathrm{~s}$ doublet splitting $\left(\Delta \mathrm{E}_{3 \mathrm{~s}}\right)$ arising from the electron exchange between the electrons in $3 \mathrm{~s}$ and $3 \mathrm{~d}$ orbitals of Mn enables a more precise assessment on the oxidation state (Fig. 2e) [40,41]. According to Beyreuther et al. [42], the AOS of Mn can be estimated using an empirical equation:

$A O S_{M n}=9.67-1.27 \Delta E_{3 s}$

The measured $\Delta \mathrm{E}_{3 \mathrm{~s}}$ for pristine $\mathrm{MnO}_{2}$ and $\mathrm{S}-\mathrm{MnO}_{2}$ is 4.98 and $4.63 \mathrm{eV}$, corresponding to AOS values of 3.35 and 3.79, respectively. The higher AOS of S- $\mathrm{MnO}_{2}$ reveals more characteristic of $\mathrm{Mn}^{4+}$ with decreased Na content from 0.45 to $0.12 \mathrm{At} \%$. The XPS spectrum of $\mathrm{O} 1 \mathrm{~s}$ (Fig. 2d) can also be utilized to estimate the valence of Mn cations. The integrated peak area of hydrated trivalent $\mathrm{Mn}-\mathrm{O}-\mathrm{H}$ bond drop from $24.8 \%$ to $18.6 \%$, corresponding to the decrease of trivalent Mn content, 


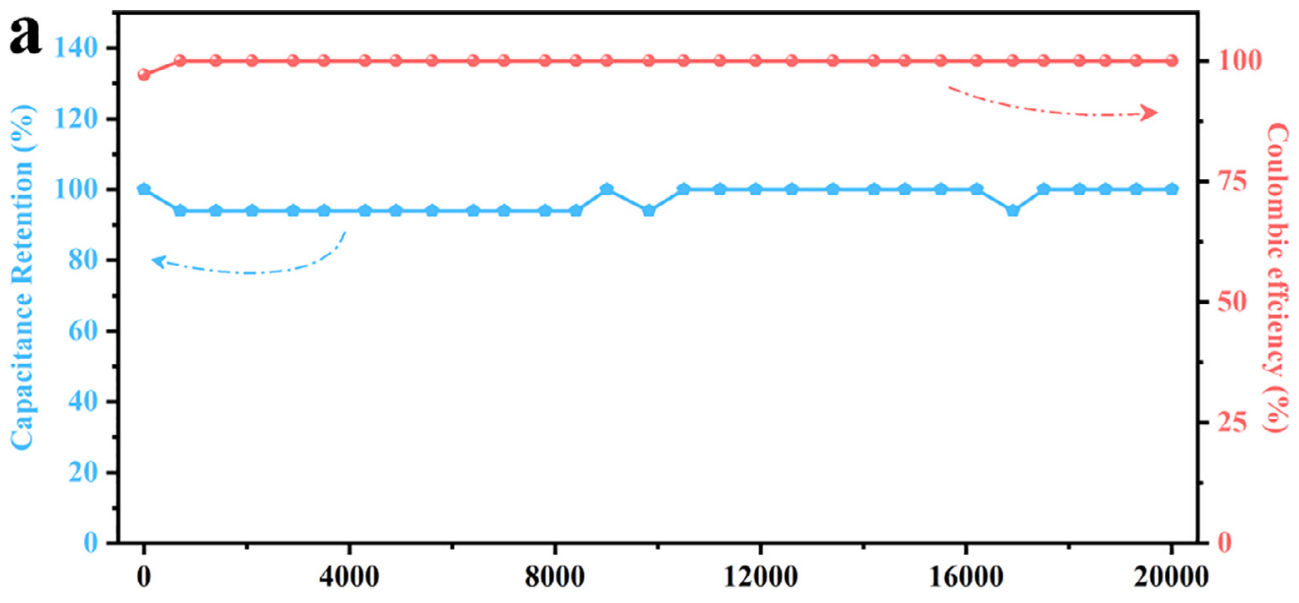

b

Cycle Number

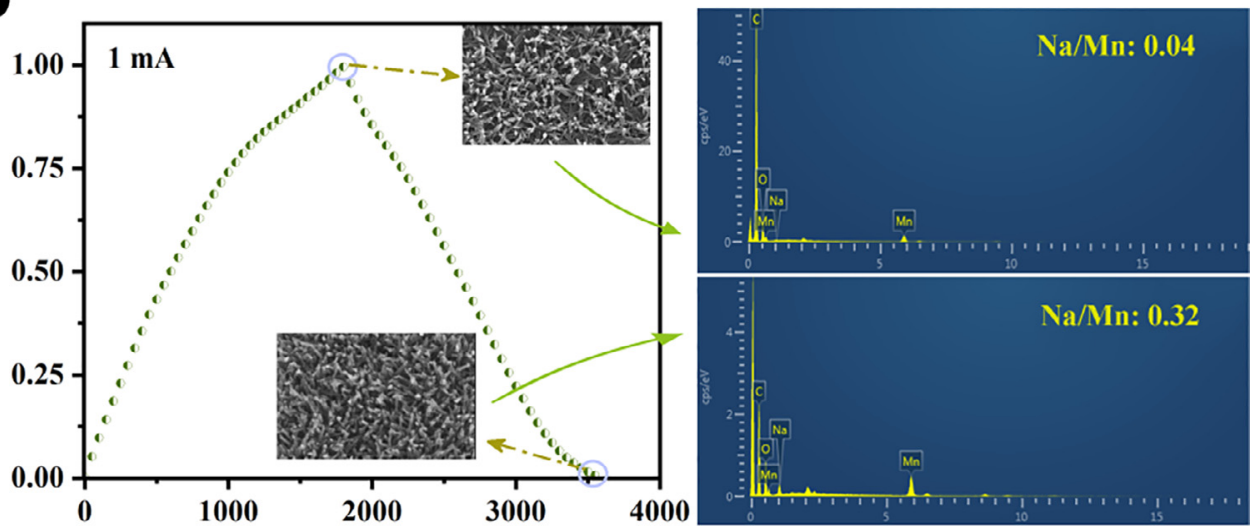

Fig. 4. (a) Cyclic stability and coulombic efficiency of S-MnO $\mathrm{M}_{2}$ (b) GCD curve at $1 \mathrm{~mA}$ of S-MnO $\mathrm{M}_{2}$ and the corresponding SEM and EDS images.

in agreement with previous data observed in $\mathrm{MnO}_{2}$ [25,32]. From the above result, it might be deduced that $\mathrm{Na}^{+}$cations in the layered $\delta$ $\mathrm{MnO}_{2}$ structure are leached away and readily available around the $\left[\mathrm{MnO}_{6}\right]$ building block as templates for directing the growth of $2 \times 2$ tunnel structure, analogous with previous studies $[28,40]$.

\section{Electrochemical performance}

Comparative electrochemical studies were conducted for the pristine $\mathrm{MnO}_{2}$ and $\mathrm{S}-\mathrm{MnO}_{2}$ electrodes in three-electrode cells containing $1 \mathrm{M} \mathrm{Na}_{2} \mathrm{SO}_{4}$ electrolyte. As depicted in Fig. 3a, b, all CV curves exhibit similar loops with almost no distortion at the sweep rates from 5 to $100 \mathrm{mV} / \mathrm{s}$, indicating a fast electrochemical response. To evaluate the electrochemical activity of both samples, the electrochemically active surface area (ECSA) was measured in the non-Faradaic potential region of CVs at multiple scan rates using the following expression $[40,43]$ :

$E S C A=\frac{C_{D L}}{m * C_{S}}$

where $\mathrm{C}_{\mathrm{DL}}$ represents the double-layer region capacitance, $\mathrm{m}$ is the mass loading of active materials, and $\mathrm{C}_{\mathrm{s}}$ is the areal capacitance for a flat standard electrode with $1 \mathrm{~cm}^{2}$ of the real surface area. $\mathrm{C}_{\mathrm{DL}}$ is obtained from the following equation:

$i_{c}=C_{D L} * v$

where $i_{c}$ is the halves of the anodic and cathodic current density difference at certain potential and $v$ is the scan rate. A plot of $i_{c}$ as a function of $v$ is illustrated in Fig. 3c. $\mathrm{C}$ DL of $\mathrm{S}-\mathrm{MnO}_{2}$ and pristine $\mathrm{MnO}_{2}$ measured from the slope of the straight line is 722.8 and $378.9 \mathrm{mF} / \mathrm{cm}^{2}$, respectively. The resulting ECSA value of $\mathrm{S}-\mathrm{MnO}_{2}\left(160.62 \mathrm{~m}^{2} / \mathrm{g}\right)$ is 2.6 times higher than that of pristine $\mathrm{MnO}_{2}\left(61.9 \mathrm{~m}^{2} / \mathrm{g}\right)$ by assuming an average $C_{s}$ value of $100 \mu \mathrm{F} / \mathrm{cm}^{2}$ [44]. The higher ECSA of the electrode after the acid-assisted hydrothermal process can been considered as an indication of more available effective active sites for ion storage due to morphology transition, strongly supporting previous BET measurement results. The amount of capacitive contribution was analyzed quantitatively according to the relationship between the peak current (i) and scan rate $(\nu): i=a \nu^{b}$ (where $\mathrm{a}$ and $\mathrm{b}$ are adjustable parameters) [45]. Usually, the exponent $(b)$ will take a value between 0.5 (diffusioncontrolled reaction) and 1 (surface-controlled reaction). As depicted in Fig. S3b, the b value of S- $\mathrm{MnO}_{2}$ determined from the slope of $\log (i)-\log$ $(\nu)$ is 0.85 for anodic peak and 0.78 for cathodic peak, demonstrating a surface-dominated kinetic process [46]. Pure electric double layer capacitance (EDLC) value of $0.49 \mathrm{~F} / \mathrm{cm}^{2}$ can be estimated from the Y-axis intercept point of the linear fitted plot in Fig. S3c. Consistent with CV results, good symmetry of the GCD curves with a small IR drop (Fig. 3d, e) confirms the formation of efficient electrochemical double layers, suggestive of a satisfactory capacitive behavior and remarkable rate capability [28]. Calculations of specific capacitance were carried out using discharge curves in GCD measurements (Fig. 3f). Compared with the pristine $\mathrm{MnO}_{2}$ electrodes, $\mathrm{S}-\mathrm{MnO}_{2}$ also shows enhanced areal capacitance and competitive rate capability with a 45 -fold increment in the current density. The above good electrochemical performances of S$\mathrm{MnO}_{2}$ could be ascribed to the unique core-branch structure, which provides many external reaction sites and results in effective utilization of active materials. To further explore the improved ion storage mechanism, EIS measurements were conducted (Fig. 3g). The smaller Xintercept and radius of the semicircle at high-medium frequencies after the acid-induced process correspond to lower $R_{s}(1.74 \Omega)$ and $R_{c t}$ $(0.20 \Omega)$, respectively, demonstrating that the $\mathrm{S}-\mathrm{MnO}_{2}$ electrode promotes the effective collection and transfer of electrons. Furthermore, Warburg coefficient $(\sigma)$, reflecting the ion diffusion impedance, can be 

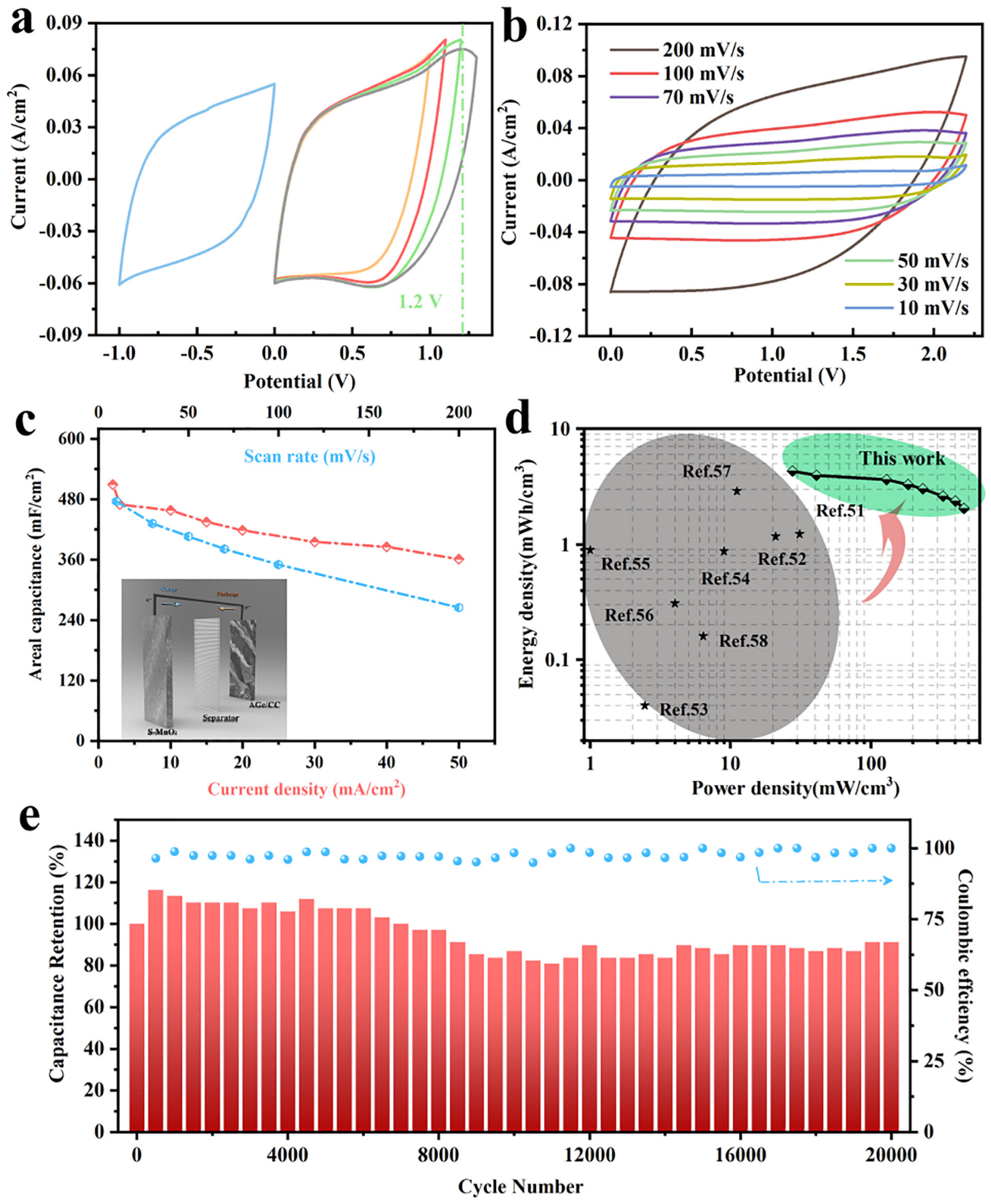

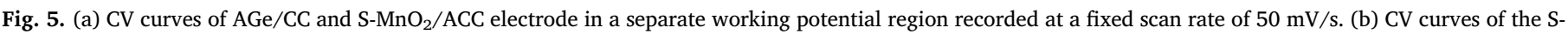

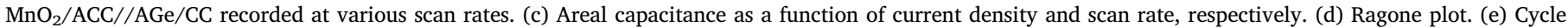
stability and corresponding Coulombic efficiency at a current density of $15 \mathrm{~mA} / \mathrm{cm}^{2}$.

obtained by quantitative analysis of the linear relationship between $\mathrm{Z}^{\prime}$ and $\mathrm{w}^{-1 / 2}[47,48]$, according to formula (4):

$Z^{\prime}=\sigma w^{-1 / 2}+R_{s}+R_{c t}$

where $\mathrm{Z}^{\prime}$ is the real part of electrochemical impedance spectroscopy, $\mathrm{w}^{-1 / 2}$ is the reciprocal of the square root of the angle frequency. The $\sigma$ value for pristine $\mathrm{MnO}_{2}$ and $\mathrm{S}-\mathrm{MnO}_{2}$ is 0.46 and 0.36 , implying the superior ion diffusion rate of the latter (Fig. $3 \mathrm{~h}$ ). It, therefore, appears conclusively that the smaller resistance and diffusion resistivity of S$\mathrm{MnO}_{2}$ through interfacial reconstruction rendered a better rate capability performance. As expected, $\mathrm{S}-\mathrm{MnO}_{2}$ shows all round raising of electrochemical performance than the pristine one (Fig. 3i). What's more, a stable capacitance with almost no decay upon 20000-cycle operations in comparison to cycle 1 is shown in Fig. 4a which records one of the best cycling performance of $\mathrm{MnO}_{2}$-based electrodes reported recently (Table S1) [3]. Apart from this, nearly 100\% Coulombic 
efficiency throughout the entire cycling process is maintained, signifying the excellent device performance. To gain further understanding on the stability issues and depth insight on the electrode kinetics of the $\mathrm{S}-\mathrm{MnO}_{2}$, we conducted XRD, EDS, and SEM investigations after electrochemical measurements. Accordingly, XRD patterns of the S- $\mathrm{MnO}_{2}$ electrode after 20,000 cycles reveal the co-existence of $\alpha$ - and $\delta$-phases (Fig. S3d), with clearly distinguishable peaks, indicative of better crystallinity during cycling test [49]. Element distribution was further mapped using EDX to the electrode charge/discharged at $1 \mathrm{~mA}$ with a negligible IR drop of $0.0038 \mathrm{~V}$ (Fig. 4b). As shown in the inset of Fig. 4b, the good preservation of morphology at a fully-charged and fully-discharged state demonstrates excellent reversibility and stability of the redox reactions. While the EDS analysis reveals an increasing mole ratio of $\mathrm{Na} / \mathrm{Mn}$ after fully discharged to $0 \mathrm{~V}$. Thus, it can be deduced that the energy storage of $\mathrm{MnO}_{2}$ is contributed mainly by the insertion/de-insertion of $\mathrm{Na}^{+}$ions. Therefore, we have reason to believe that the exceptional long-term stability of S- $\mathrm{MnO}_{2}$ can be rationalized by the inhibition of unstable $\mathrm{MnOOH}$ disproportionation during cycling [19,50-52].

The plausible reasons for the superior performance of $\mathrm{S}-\mathrm{MnO}_{2}$ are schematically articulated as follows. First, two phases can form a stable heterophase junction with improved electric conductivity than that of the single-phase, related to the larger conduction band of tunneled structure [32]. Second, the needle-shaped $\mathrm{MnO}_{2}$ with small aspect ratio grown upwardly on both sides of multi-layered $\mathrm{MnO}_{2}$ lamella constructs a hierarchically continuing skeleton capable of exposing more electrochemically active sites and hence provides more efficient and convenient channels for the rapid transfer of electrolyte ions. Third, the voids between two layers can act as "ion reservoir" to buffer the sharp change of ion concentration, which is regarded as a key site for strong electrolyte binding and fast charge-discharge ability. Finally, the decreasing ratio of $\mathrm{Mn}^{3+} / \mathrm{Mn}^{4+}$ in $\mathrm{S}-\mathrm{MnO}_{2}$ endows the electrode with lower catalytic activity, as $\mathrm{Mn}^{3+}$ has been identified as more electrochemically active by various studies, greatly contributing to the stability of electrodes in high-voltage region $[40,53,54]$.

Because more positive potential can be achieved (Fig. 5a), the oxygen evolution reaction is supposed to be kinetically limited. As discussed in the previous section, the possibility of the extended potential window can be ascribed to the decreasing ratio of trivalent $\mathrm{Mn}$ in the bulk structure of $\mathrm{S}-\mathrm{MnO}_{2}$, which may hinder its catalytic activity [55]. In this way, the assembled device can avoid the decomposition of aqueous electrolyte under an operation voltage $2.2 \mathrm{~V}$, corroborating the safe performance with near square-shape $\mathrm{CV}$ at a high scan rate of $200 \mathrm{mV} / \mathrm{s}$ and linear current-voltage relationship during GCD tests (Fig. 5b, S4). These in turn reveal ultrafast charge transfer and ions mobility [56-58]. Notably, the total areal capacitance, calculated from the slope of the discharge curve, reaches 509.1 and $361.4 \mathrm{mF} / \mathrm{cm}^{2}$ at the current densities of 2 and $50 \mathrm{~mA} / \mathrm{cm}^{2}$ (Fig. 5c), respectively, implying an exceptional rate capability. Together, the achievement of high areal capacitance, outstanding rate capability, and wide voltage window of $2.2 \mathrm{~V}$ ultimately underpin the device with high-level energy and power performance. The highest energy density based on the total volume of the flexible device is estimated to be $4.3 \mathrm{mWh} / \mathrm{cm}^{2}$ at the power density of $27.6 \mathrm{~mW} / \mathrm{cm}^{2}$. The device still demonstrates reasonable performance $\left(2.0 \mathrm{mWh} / \mathrm{cm}^{2}\right)$ at even higher power density $\left(461.6 \mathrm{~mW} / \mathrm{cm}^{2}\right)$, outperforming many of the previously reported supercapacitor devices and even reaching the level of thin-film lithium battery $\left(0.3-10 \mathrm{mWh} / \mathrm{cm}^{3}\right.$ ) (Fig. 5d) [59-67]. A GCD test was performed to characterize the cycling performance. A gradual capacitance increase in the first thousands of cycles, indicative of enhanced EDLC and Mn III/IV redox reaction, presumably results from the deeply insertion of $\mathrm{Na}^{+}$to form ions diffusion paths during the dissolution-redeposition process of the $\mathrm{MnO}_{2}$. Besides, remarkably consistent capacitance retention of $\sim 91.2 \%$ (with Coulombic efficiency of $\sim 100 \%$ ) is achieved over 20,000 cycles with only $0.00044 \%$ fading per cycle (Fig. 5e), which highlights the scalability of multi-layered sawtooth
$\mathrm{MnO}_{2}$ nanostructure as an electrode for flexible electronics applications.

\section{Conclusions}

In summary, we have reported a facile acid-assisted hydrothermal approach for tuning both the crystallographic phase (from the layer phase to the tunnel phases) and the morphology of nanostructured $\mathrm{MnO}_{2}$. The heterogeneous and hierarchical $\mathrm{MnO}_{2}$ structure delivers all round enhancement of electrochemical performance than the pristine one. The phase transition toward more electrokinetically favored crystallographic structure and the optimum morphology for exposing abundant electrochemically active surfaces synergize to deliver the observed superior performance. A wide operating voltage of $2.2 \mathrm{~V}$ can be achieved from the assembled asymmetric device. Benefitted from the interconnected sawtooth-shape in $\mathrm{S}-\mathrm{MnO}_{2} / \mathrm{ACC} / / \mathrm{AGe} / \mathrm{CC}$, our device guarantees a fast ion migration channel delivering areal capacitance and volumetric energy density of $590.1 \mathrm{mF} / \mathrm{cm}^{2}$ and $4.3 \mathrm{mWh} / \mathrm{cm}^{2}$ at $2 \mathrm{~mA} / \mathrm{cm}^{2}$ respectively. This work provides a new insight to design commercially viable electrochemical storage devices by tuning the phase and correlating to electronic property.

\section{Declaration of Competing Interest}

The authors declare that they have no known competing financial interests or personal relationships that could have appeared to influence the work reported in this paper.

\section{Acknowledgments}

This work was supported by the Fund of State Key Laboratory of Multiphase Complex Systems (No. MPCS-2019-A-03) Institute of Process Engineering, Chinese Academy of Sciences.

\section{Appendix A. Supplementary data}

Supplementary data to this article can be found online at https:// doi.org/10.1016/j.cej.2020.124293.

\section{References}

[1] P. Huang, C. Lethien, S. Pinaud, K. Brousse, R. Laloo, V. Turq, M. Respaud, A. Demortiere, B. Daffos, P.-L. Taberna, On-chip and freestanding elastic carbon films for micro-supercapacitors, Science 351 (2016) 691.

[2] M. Beidaghi, Y. Gogotsi, Capacitive energy storage in micro-scale devices: recent advances in design and fabrication of micro-supercapacitors, Energy \& Environ. Sci. 7 (2014) 867.

[3] Y. Hu, Y. Wu, J. Wang, Manganese-oxide-based electrode materials for energy storage applications: how close are we to the theoretical capacitance? Adv. Mater. 30 (2018) 1802569.

[4] J. Liang, G. Zhu, C. Wang, Y. Wang, H. Zhu, Y. Hu, H. Lv, R. Chen, L. Ma, T. Chen, Z. Jin, J. Liu, $\mathrm{MoS}_{2}$-based all-purpose fibrous electrode and self-powering energy fiber for efficient energy harvesting and storage, Adv. Energy Mater. 7 (2017) 1601208.

[5] W. Liu, N. Liu, Y. Shi, Y. Chen, C. Yang, J. Tao, S. Wang, Y. Wang, J. Su, L. Li, A wire-shaped flexible asymmetric supercapacitor based on carbon fiber coated with a metal oxide and a polymer, J. Mater. Chem. A 3 (2015) 13461.

[6] M. He, K. Fic, E. Fra, P. Novák, E.J. Berg, Ageing phenomena in high-voltage aqueous supercapacitors investigated by in situ gas analysis, Energy Environ. Sci. 9 (2016) 623.

[7] Y. Song, P. Deng, Z. Qin, D. Feng, D. Guo, X. Sun, X.-X. Liu, A polyanionic molybdenophosphate anode for a $2.7 \mathrm{~V}$ aqueous pseudocapacitor, Nano Energy 65 (2019) 104010 .

[8] G. Zhu, L. Ma, H. Lin, P. Zhao, L. Wang, Y. Hu, R. Chen, T. Chen, Y. Wang, Z. Tie, Z. Jin, High-performance Li-ion capacitor based on black- $\mathrm{TiO}_{2-\mathrm{x}} /$ graphene aerogel anode and biomass-derived microporous carbon cathode, Nano Res. 12 (2019) 1713.

[9] G. Zhu, T. Chen, L. Wang, L. Ma, Y. Hu, R. Chen, Y. Wang, C. Wang, W. Yan, Z. Tie, High energy density hybrid lithium-ion capacitor enabled by $\mathrm{Co}_{3} \mathrm{ZnC@} \mathrm{N-doped}$ carbon nanopolyhedra anode and microporous carbon cathode, Energy Storage Mater. 14 (2018) 246.

[10] G. Zhu, L. Ma, H. Lv, Y. Hu, T. Chen, R. Chen, J. Liang, X. Wang, Y. Wang, C. Yan, Z. Tie, Z. Jin, J. Liu, Pine needle-derived microporous nitrogen-doped carbon 
frameworks exhibit high performances in electrocatalytic hydrogen evolution reaction and supercapacitors, Nanoscale 9 (2017) 1237.

[11] G. Zhu, T. Chen, Y. Hu, L. Ma, R. Chen, H. Lv, Y. Wang, J. Liang, X. Li, C. Yan, H. Zhu, H. Liu, Z. Tie, Z. Jin, J. Liu, Recycling PM 2.5 carbon nanoparticles generated by diesel vehicles for supercapacitors and oxygen reduction reaction, Nano Energy 33 (2017) 229.

[12] Z.-H. Huang, Y. Song, D.-Y. Feng, Z. Sun, X. Sun, X.-X. Liu, High mass loading $\mathrm{MnO}_{2}$ with hierarchical nanostructures for supercapacitors, ACS Nano 12 (2018) 3557.

[13] W. Wei, X. Cui, W. Chen, D.G. Ivey, Manganese oxide-based materials as electrochemical supercapacitor electrodes, Chem. Soc. Rev. 40 (2011) 1697.

[14] M. Toupin, T. Brousse, D. Bélanger, Charge storage mechanism of $\mathrm{MnO}_{2}$ electrode used in aqueous electrochemical capacitor, Chem. Mater. 16 (2004) 3184.

[15] G. Wang, L. Zhang, J. Zhang, A review of electrode materials for electrochemical supercapacitors, Chem. Soc. Rev. 41 (2012) 797.

[16] J.E. Post, Manganese oxide minerals: Crystal structures and economic and environmental significance, Proc. Natl. Acad. Sci. 96 (1999) 3447.

[17] Q. Feng, H. Kanoh, K. Ooi, Manganese oxide porous crystals, J. Mater. Chem. 9 (1999) 319.

[18] Y. Song, T. Liu, B. Yao, M. Li, T. Kou, Z.-H. Huang, D.-Y. Feng, F. Wang, Y. Tong, X.X. Liu, Y. Li, Ostwald ripening improves rate capability of high mass loading manganese oxide for supercapacitors, ACS Energy Lett. 2 (2017) 1752.

[19] Z. Ma, F. Jing, Y. Fan, L. Hou, L. Su, L. Fan, G. Shao, High-stability $\mathrm{MnO}_{\mathrm{x}}$ nanowires@C@MnO nanosheet core-shell heterostructure pseudocapacitance electrode based on reversible phase transition mechanism, Small. 15 (2019) 1900862.

[20] C. Zhu, L. Yang, J.K. Seo, X. Zhang, S. Wang, J. Shin, D. Chao, H. Zhang, Y.S. Meng, H.J. Fan, Self-branched $\alpha-\mathrm{MnO}_{2} / \delta-\mathrm{MnO}_{2}$ heterojunction nanowires with enhanced pseudocapacitance, Mater. Horiz. 4 (2017) 415.

[21] S. Zhu, L. Li, J. Liu, H. Wang, T. Wang, Y. Zhang, L. Zhang, R.S. Ruoff, F. Dong, Structural directed growth of ultrathin parallel birnessite on $\beta-\mathrm{MnO}_{2}$ for high-performance asymmetric supercapacitors, ACS Nano 12 (2018) 1033.

[22] S. Lee, G. Nam, J. Sun, J.S. Lee, H.W. Lee, W. Chen, J. Cho, Y. Cui, Enhanced Intrinsic catalytic activity of $\lambda-\mathrm{MnO}_{2}$ by electrochemical tuning and oxygen vacancy generation, Angew. Chem. Int. Ed. 55 (2016) 8599.

[23] A. Taguchi, S. Inoue, S. Akamaru, M. Hara, K. Watanabe, T. Abe, Phase transition and electrochemical capacitance of mechanically treated manganese oxides, J. Alloy. Compd. 414 (2006) 137.

[24] M. Song, H. Tan, D. Chao, H.J. Fan, Recent advances in zn-ion batteries, Adv. Funct. Mater. 28 (2018) 1802564.

[25] L. Yang, S. Cheng, J. Wang, X. Ji, Y. Jiang, M. Yao, P. Wu, M. Wang, J. Zhou, M. Liu, Investigation into the origin of high stability of $\delta-\mathrm{MnO}_{2}$ pseudo-capacitive electrode using operando Raman spectroscopy, Nano Energy 30 (2016) 293.

[26] J. Zhang, J. Sun, T.A. Shifa, D. Wang, X. Wu, Y. Cui, Hierarchical $\mathrm{MnO}_{2}$ /activated carbon cloth electrode prepared by synchronized electrochemical activation and oxidation for flexible asymmetric supercapacitors, Chem. Eng. J. 372 (2019) 1047.

[27] D. Portehault, S. Cassaignon, E. Baudrin, J.-P. Jolivet, Morphology control of cryptomelane type $\mathrm{MnO}_{2}$ nanowires by soft chemistry. Growth mechanisms in aqueous medium, Chem. Mater. 19 (2007) 5410.

[28] Y. Guo, L. Li, L. Song, M. Wu, Y. Gao, J. Chen, C. Mao, J. Song, H. Niu, Co ${ }^{2}$ induced phase transformation from $\delta$-to $\alpha-\mathrm{MnO}_{2}$ and their hierarchical $\alpha-\mathrm{MnO}_{2} @ \delta$ $\mathrm{MnO}_{2}$ nanostructures for efficient asymmetric supercapacitors, J. Mater. Chem. A 7 (2019) 12661.

[29] K. Yu, X. Pan, G. Zhang, X. Liao, X. Zhou, M. Yan, L. Xu, L. Mai, Nanowires in energy storage devices: structures, synthesis, and applications, Adv. Energy Mater. 8 (2018) 1802369.

[30] Y. Li, J. Wang, Y. Zhang, M.N. Banis, J. Liu, D. Geng, R. Li, X. Sun, Facile controlled synthesis and growth mechanisms of flower-like and tubular $\mathrm{MnO}_{2}$ nanostructures by microwave-assisted hydrothermal method, J. Colloid Interface Sci. 369 (2012) 123.

[31] Y.D. Li, X.L. Li, R.R. He, J. Zhu, Z.X. Deng, Artificial lamellar mesostructures to $\mathrm{WS}_{2}$ nanotubes, J. Am. Chem. Soc. 124 (2002) 1411.

[32] Y.-F. Li, S.-C. Zhu, Z.-P. Liu, Reaction network of layer-to-tunnel transition of $\mathrm{MnO}_{2}$, J. Am. Chem. Soc. 138 (2016) 5371.

[33] X.F. Shen, Y.S. Ding, J. Liu, J. Cai, K. Laubernds, R.P. Zerger, A. Vasiliev, M. Aindow, S.L. Suib, Control of nanometer-scale tunnel sizes of porous manganese oxide octahedral molecular sieve nanomaterials, Adv. Mater. 17 (2005) 805.

[34] X. Wang, Y. Li, Synthesis and formation mechanism of manganese dioxide nanowires/nanorods, Chemistry-A, Eur. J. 9 (2003) 300.

[35] W.-Y. Ko, Y.-C. Liu, J.-Y. Lai, C.-C. Chung, K.-J. Lin, Vertically standing $\mathrm{mno}_{2}$ nanowalls grown on AgCNT-modified carbon fibers for high-performance supercapacitors, ACS Sustain. Chem. Eng. 7 (2018) 669.

[36] C. Julien, M. Massot, R. Baddour-Hadjean, S. Franger, S. Bach, J. Pereira-Ramos, Raman spectra of birnessite manganese dioxides, Solid State Ionics 159 (2003) 345.

[37] C. Julien, M. Massot, C. Poinsignon, Lattice vibrations of manganese oxides: Part I. Periodic structures, Spectroch. Acta Part A Mol. Biomol. Spectroscopy 60 (2004) 689.

[38] T. Gao, H. Fjellvåg, P. Norby, A comparison study on Raman scattering properties of $\alpha$-and $\beta-\mathrm{MnO}_{2}$, Anal. Chim. Acta 648 (2009) 235.

[39] C. Zhu, G. Fang, J. Zhou, J. Guo, Z. Wang, C. Wang, J. Li, Y. Tang, S. Liang, Binderfree stainless steel@ $\mathrm{Mn}_{3} \mathrm{O}_{4}$ nanoflower composite: a high-activity aqueous zinc-ion battery cathode with high-capacity and long-cycle-life, J. Mater. Chem. A 6 (2018) 9677.

[40] G. Yan, Y. Lian, Y. Gu, C. Yang, H. Sun, Q. Mu, Q. Li, W. Zhu, X. Zheng, M. Chen,
Phase and morphology transformation of $\mathrm{MnO}_{2}$ induced by ionic liquids toward efficient water oxidation, ACS Catal. 8 (2018) 10137.

[41] M. Chigane, M. Ishikawa, Manganese oxide thin film preparation by potentiostatic electrolyses and electrochromism, J. Electrochem. Soc. 147 (2000) 2246.

[42] E. Beyreuther, S. Grafström, L.M. Eng, C. Thiele, K. Dörr, XPS investigation of Mn valence in lanthanum manganite thin films under variation of oxygen content, Phys. Rev. B 73 (2006) 155425.

[43] C.C. McCrory, S. Jung, J.C. Peters, T.F. Jaramillo, Benchmarking heterogeneous electrocatalysts for the oxygen evolution reaction, J. Am. Chem. Soc. 135 (2013) 16977.

[44] S. Sankar, H. Lee, H. Jung, A. Kim, A.T.A. Ahmed, A.I. Inamdar, H. Kim, S. Lee, H. Im, D.Y. Kim, Ultrathin graphene nanosheets derived from rice husks for sustainable supercapacitor electrodes, New J. Chem. 41 (2017) 13792.

[45] H. Lindström, S. Södergren, A. Solbrand, H. Rensmo, J. Hjelm, A. Hagfeldt, S. E. Lindquist, $\mathrm{Li}^{+}$ion insertion in $\mathrm{TiO}_{2}$ (anatase). 1. Chronoamperometry on CVD films and nanoporous films, J. Phys. Chem. B 101 (1997) 7710.

[46] Q. Xue, H. Gan, Y. Huang, M. Zhu, Z. Pei, H. Li, S. Deng, F. Liu, C. Zhi, Boron element nanowires electrode for supercapacitors, Adv. Energy Mater. 8 (2018) 1703117.

[47] X.L. Wu, Y.G. Guo, J. Su, J.W. Xiong, Y.L. Zhang, L.J. Wan, Carbon-nanotube-decorated nano-LiFePO${ }_{4} @$ C cathode material with superior high-rate and low-temperature performances for lithium-ion batteries, Adv. Energy Mater. 3 (2013) 1155

[48] J. Yu, C. Yu, W. Guo, Z. Wang, S. Li, J. Chang, X. Tan, Y. Ding, M. Zhang, L. Yang, Decoupling and correlating the ion transport by engineering 2D carbon nanosheets for enhanced charge storage, Nano Energy 64 (2019) 103921.

[49] H. Xia, Y.S. Meng, X. Li, G. Yuan, C. Cui, Porous manganese oxide generated from lithiation/delithiation with improved electrochemical oxidation for supercapacitors, J. Mater. Chem. 21 (2011) 15521.

[50] Q. Zhang, C. Didier, W.K. Pang, Y. Liu, Z. Wang, S. Li, V.K. Peterson, J. Mao, Z. Guo Structural insight into layer gliding and lattice distortion in layered manganese oxide electrodes for potassium-ion batteries, Adv. Energy Mater. (2019) 1900568.

[51] A. áRobert Armstrong, The intercalation compound $\mathrm{Li}\left(\mathrm{Mn}_{0.9} \mathrm{Co}_{0.1}\right) \mathrm{O}_{2}$ as a positive electrode for rechargeable lithium batteries, Chem. Commun. (1998) 1833.

[52] K. Zhang, D. Kim, Z. Hu, M. Park, G. Noh, Y. Yang, J. Zhang, V.W.-H. Lau, S.L. Chou, M. Cho, Manganese based layered oxides with modulated electronic and thermodynamic properties for sodium ion batteries, Nat. Commun. 10 (2019) 5203.

[53] Y. Gorlin, B. Lassalle-Kaiser, J.D. Benck, S. Gul, S.M. Webb, V.K. Yachandra, J. Yano, T.F. Jaramillo, In situ X-ray absorption spectroscopy investigation of a bifunctional manganese oxide catalyst with high activity for electrochemical water oxidation and oxygen reduction, J. Am. Chem. Soc. 135 (2013) 8525.

[54] V. Tripkovic, H.A. Hansen, T. Vegge, Computational screening of doped $\alpha-\mathrm{MnO}_{2}$ catalysts for the oxygen evolution reaction, ChemSusChem 11 (2018) 629.

[55] M.M. Najafpour, G. Renger, M. Hołyńska, A.N. Moghaddam, E.-M. Aro, R. Carpentier, H. Nishihara, J.J. Eaton-Rye, J.-R. Shen, S.I. Allakhverdiev, Manganese compounds as water-oxidizing catalysts: from the natural water-oxidizing complex to nanosized manganese oxide structures, Chem. Rev. 116 (2016) 2886.

[56] J. Chang, M. Jin, F. Yao, T.H. Kim, V.T. Le, H. Yue, F. Gunes, B. Li, A. Ghosh, S. Xie, Asymmetric supercapacitors based on graphene/ $\mathrm{MnO}_{2}$ nanospheres and graphene/ $\mathrm{MoO}_{3}$ nanosheets with high energy density, Adv. Funct. Mater. 23 (2013) 5074.

[57] G.-R. Li, Z.-L. Wang, F.-L. Zheng, Y.-N. Ou, Y.-X. Tong, ZnO@ $\mathrm{MoO}_{3}$ core/shell nanocables: facile electrochemical synthesis and enhanced supercapacitor performances, J. Mater. Chem. 21 (2011) 4217.

[58] J. Kang, A. Hirata, L. Kang, X. Zhang, Y. Hou, L. Chen, C. Li, T. Fujita, K. Akagi, M. Chen, Enhanced supercapacitor performance of $\mathrm{MnO}_{2}$ by atomic doping, Angew. Chem. Int. Ed. 52 (2013) 1664.

[59] D. Pech, M. Brunet, H. Durou, P. Huang, V. Mochalin, Y. Gogotsi, P.-L. Taberna, P. Simon, Ultrahigh-power micrometre-sized supercapacitors based on onion-like carbon, Nat. Nanotechnol. 5 (2010) 651.

[60] C. Xu, Z. Li, C. Yang, P. Zou, B. Xie, Z. Lin, Z. Zhang, B. Li, F. Kang, C.P. Wong, An ultralong, highly oriented nickel-nanowire-array electrode scaffold for high-performance compressible pseudocapacitors, Adv. Mater. 28 (2016) 4105.

[61] Z. Pan, Y. Qiu, J. Yang, F. Ye, Y. Xu, X. Zhang, M. Liu, Y. Zhang, Ultra-endurance flexible all-solid-state asymmetric supercapacitors based on three-dimensionally coated $\mathrm{MnO}_{\mathrm{x}}$ nanosheets on nanoporous current collectors, Nano Energy 26 (2016) 610.

[62] P. Yang, X. Xiao, Y. Li, Y. Ding, P. Qiang, X. Tan, W. Mai, Z. Lin, W. Wu, T. Li, Hydrogenated ZnO core-shell nanocables for flexible supercapacitors and selfpowered systems, ACS Nano 7 (2013) 2617.

[63] T. Zhai, X. Lu, Y. Ling, M. Yu, G. Wang, T. Liu, C. Liang, Y. Tong, Y. Li, A New benchmark capacitance for supercapacitor anodes by mixed-valence sulfur-doped $\mathrm{V}_{6} \mathrm{O}_{13-x}$, Adv. Mater. 26 (2014) 5869.

[64] Y. Zeng, Y. Han, Y. Zhao, Y. Zeng, M. Yu, Y. Liu, H. Tang, Y. Tong, X. Lu, Advanced Ti-doped $\mathrm{Fe}_{2} \mathrm{O}_{3} @$ PEDOT core/shell anode for high-energy asymmetric supercapacitors, Adv. Energy Mater. 5 (2015) 1402176.

[65] Q. Tang, M. Chen, C. Yang, W. Wang, H. Bao, G. Wang, Enhancing the energy density of asymmetric stretchable supercapacitor based on wrinkled CNT@ $\mathrm{MnO}_{2}$ cathode and CNT@polypyrrole anode, ACS Appl. Mater. Interfaces 7 (2015) 15303.

[66] G. Yang, X.-X. Liu, Electrochemical fabrication of interconnected tungsten bronze nanosheets for high performance supercapacitor, J. Power Sour. 383 (2018) 17.

[67] S. Cho, B. Patil, S. Yu, S. Ahn, J. Hwang, C. Park, K. Do, H. Ahn, Flexible, swiss roll, fiber-shaped, asymmetric supercapacitor using $\mathrm{MnO}_{2}$ and $\mathrm{Fe}_{2} \mathrm{O}_{3}$ on carbon fibers, Electrochim. Acta 269 (2018) 499. 